\title{
Research on quality and standard two-way intelligent matching algorithm based on similarity theory
}

\author{
Zhaojun Wang, Liangwen Yue ${ }^{\mathrm{a}, *}$ \\ Beijing Sunway World Science \& Technology Co.,Ltd; Bldg 12,Yard 6, Haiying \\ Road,Fengtai District,Beijing,China,100070 \\ aliangwenylw@163.com \\ *corresponding author
}

\begin{abstract}
This paper discussed the model and algorithm of two-way intelligent matching between product quality and standard, and selected randomly 18 kinds of men's shirts products from Tmall Mall, and conducted the empirical test of two-way matching between product quality and standard with the designed standard,aiming at the limitation of the research on two-way intelligent matching at home and abroad, based on the fuzzy similarity theory in fuzzy mathematics. Through empirical test, it is found that the two-way matching model and algorithm given in this study is a universal, scientific and reasonable two-way matching model and algorithm of product quality and standard, which can support most of the two-way matching of product quality and standard, not only can enrich the two-way matching theory of product quality and standard, but also can be applied to the practice of economic and social development. The model and algorithm supports the two-way automatic matching of product quality and standard, and provides an important methodology for the research of National Quality Infrastructure (NQI) common technology.
\end{abstract}

KEYWORDS: similarity algorithm, intelligent matching algorithm, standard attribute, quality attribute, matching rule

\section{Introduction}

At present, China has identified quality power as an important national strategy, and clearly put forward to improve quality and efficiency as a new engine of economic and social development, especially to strengthen the national quality and technology infrastructure. To accelerate the construction of National Quality Infrastructure (NQI), carrying out research on common technology of NQI, improving the integrated service level of NQI, and realizing one-stop service of measurement, standard, certification and accreditation, and inspection and detection 
Academic Journal of Computing \& Information Science

ISSN 2616-5775 Vol. 3, Issue 1: 1-16, DOI: 10.25236/AJCIS.030101

have become the urgent need of economic development and the endogenous demand of supply improvement. Quality and standard are inseparable. Standard is the basis of quality and quality is the result of implementing standard. As an important part of the research on NQI common technology, the research on two-way intelligent matching between product quality and standard is not perfect. Therefore, research on the theory, model, algorithm, tool and experimental verification method systematically of two-way matching between product quality and standard can improve the theory and practice of two-way matching between product quality and standard, so as to promote the research on NQI common technology. Based on the theory of fuzzy similarity in fuzzy mathematics, this paper constructed a two-way matching model of product quality and standard, and selected randomly 18 kinds of men's shirt products from Tmall Mall, and verified the two-way matching experiment of product quality and standard with the designed standard.

\section{A review of research on related issues}

\subsection{Literature review of related issues}

Generally speaking, the research results of NQI common technology, especially the two-way matching model and algorithm of product quality and standard, are few. The literature review related to this study is as follows.

$\mathrm{Li}$ and Pei ${ }^{[1]}$ discussed the problem of constructing fuzzy similarity algorithm by limiting equivalent function. Liu etc. ${ }^{[2]}$ studied the method of constructing three decision-making with intuitionistic fuzzy similarity algorithm. Zheng [3] systematically discusses the algorithm of a type of fuzzy similarity. Zhao and Xiao ${ }^{[4]}$ discussed the related problems of fuzzy similarity and developed a practical application case. Huang et $\mathrm{al}^{[5]}$ discussed the application of big data technology in intelligent matching, designed relevant algorithms, and discussed the application in production practice. Gao ${ }^{[6]}$ studies the construction of generalized Mamdani fuzzy system with fuzzy similarity theory, and verifies its application value with typical cases in practice. $\mathrm{Li}$ and $\mathrm{Zhu}^{[7]}$ discussed how to build decision theory and method by using fuzzy similarity theory and algorithm. Wu et al ${ }^{[8]}$ constructed the related problems of collaborative filtering method based on the user fuzzy similarity theory and algorithm. Wang and $\mathrm{Li}^{\left[{ }^{[9]}\right.}$ used intuitionistic fuzzy similarity theory and method to build an ideal solution ranking method, and the application of this method in practice verified its rationality and applicability. Zhang et $\mathrm{al}^{[10]}$ constructed the geometric deformation evaluation problem with the fuzzy similarity theory and method. Yuan and pan ${ }^{[11]}$ constructed clustering algorithm with new intuitionistic fuzzy similarity theory and method. Mathews et al. ${ }^{[12]}$ discussed the model construction of quality management infrastructure in the field of health care, which has been well applied in the department quality management implemented by Johns Hopkins Hospital. Miao et al ${ }^{[13]}$ constructed a bilateral matching model in B2B export cross-border e-commerce and conducted an example verification. Li et al ${ }^{[14]}$ constructed a bilateral data matching model and algorithm, and discussed the application in sharing economy and mobile Internet. Wan et al ${ }^{[15]}$ discussed the 
problem of building a data similarity model of wireless sensor network based on the theory of fuzzy mean. The model can solve the problem of limited resources of the Internet of things system and has better practical application value. Hussian and Yang ${ }^{[16]}$ use the theory of Pythagoras fuzzy set and similarity to build a multi criteria decision model, and carry out an example verification. The data verification results show that the method proposed in this paper is practical and feasible.

\subsection{Limitations of existing research}

Generally speaking, there are few theories about NQI common technology research at home and abroad, especially the model and algorithm of two-way matching between product quality and standard, which are in the initial and exploration stage as a whole. This paper discussed how to enrich and develop the research of two-way matching between product quality and standard.

\section{Two-way matching model of quality and standard}

Based on the theory of fuzzy similarity in fuzzy mathematics, this paper constructs a two-way matching model of product quality and standard. The schematic diagram of the model is shown in Figure 1. In Figure 1, Q stands for Quality, S stands for Standard, R stands for Rule.Quality Rule represents the matching rule between product quality and product standard. Standard rule represents the matching rule between product standard and product quality. Quality and standard are inseparable. Standards are the basis of quality, and quality is the result of implementing standards. Matching Rule represents two-way intelligent matching rules between product quality and product standard.

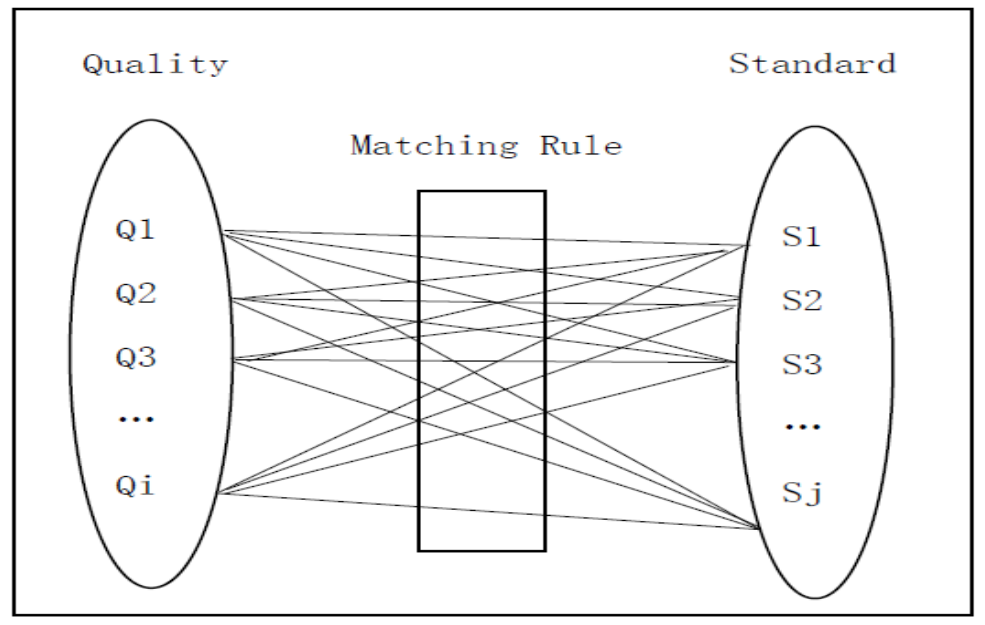

Figure 1 Two-way matching model of product quality and standard 
There are two main objects in the matching process, namely product quality and product standard. Let the set of product quality entities be $Q=\{Q 1, Q 2, \ldots, Q i\}$, Qi means $\mathrm{i}(\mathrm{i}=1,2, \ldots, \mathrm{k})$ product quality; the main body set of product standard is $\mathrm{S}=$ $\{\mathrm{S} 1, \mathrm{~S} 2, \ldots, \mathrm{Sj}\}, \mathrm{Sj}$ is the $\mathrm{j}(\mathrm{j}=1,2, \ldots \mathrm{p})$ standards. The matching attributes are [classification, identification, representation, SA], where "classification"represents standard type, "identification"represents standard name,"represent"means standard expression, and "SA"represents standard attribute. "Qclassification"refers to the standard type required by the product quality entity, and"Sclassification"refers to the standard type provided by the standard entity. Set the standard name set corresponding to the quality entity as Qidentification $=\{$ Qidentification1, Qidentification2,...,Qidentificationi $\}, \quad$ The standard name set provided by the standard subject is Sidentification $=\{$ Sidentification1,Sidentification2,...,Sidentificationj $\}$, "sidentificationj"represents the standard name of $\mathrm{Sj}$. The set of standard expression corresponding to quality subject is Qrepresent $=\{$ Qrepresent1,Qrepresent2,...,Qrepresenti $\}$, , Qrepresenti”represents the expression of Qi; the set of standard expressions provided by the standard subject is Srepresent $=\{$ Srepresent 1,Srepresent2,...,Srepresentj $\}$, “Srepresentj”represents Sj's expression.

Standard Attribute (SA) refers to the collection of various attribute indicators of a standard. Standard attributes include: standard level (which can be divided into International standards, national standards, industrial standards, local standards, group standards, enterprise standards,etc.), time range of standard application (applicable time limit, etc.), applicable field of standard (electronic information field) , food field, drug field, mechanical product field, etc.), standard availability and standard implementation difficulty. QSA $=\{\mathrm{QSA} 1, \mathrm{QSA} 2, \ldots, \mathrm{QSAn}\}$ is the attribute index set of quality subject to Standard Attribute (SA). QSAn is $\mathrm{n}(\mathrm{n}=$ $1,2, \ldots, \mathrm{q})$ indicators; $\mathrm{SQA}=\{\mathrm{SQA} 1, \mathrm{SQA} 2, \ldots, \mathrm{SQAm}\}$ is the set of attribute indexes expected by the standard subject to the quality subject. SQAm is the $\mathrm{m}(\mathrm{m}=1,2, \ldots, \mathrm{t})$ indicators.

Product Quality Qttribute (QA) includes product service life, product function perfection and product appearance novelty. The longer the service life of the product, the better the durability and stability of the product; the more perfect the product function, the stronger the ability of the product to meet the needs of the user; the more novel the product appearance, the better the appearance quality of the product, and meet the aesthetic needs of the user. These three indicators are the most important indicators to describe the quality attributes. Take men's shirt products for example. They have long service life, perfect functions (warm in winter and cool in summer, good air permeability, comfortable, etc.) and good appearance. We can basically say that the quality of this shirt is good.

The matching process is the selection process that quality subject provides standard subject according to its quality. Firstly, the standard is selected for the first time according to the corresponding standard category of the quality subject, and the obviously unqualified standard is excluded. Then according to the characteristics of quality and standard, measures the similarity degree, and Simi compares the 
similarity degree of “Qidentification”and“Sidentification”. Simr measures the similarity between "Qrepressant”and "Sreepressant”. Sim(i,r) measures the similarity between “identification”and“represent”. Next,we do a two-way match between quality and standard attributes. SimQSA measures the similarity between the attributes expected by the quality subject to the standard and the attributes of the standard itself; SimSQA measures the similarity between the attributes expected by the standard subject to the quality and the attributes of the quality itself. $\operatorname{Sim}(\mathrm{i}, \mathrm{r}, \mathrm{QSA}, \mathrm{SQA})$ is used to measure the similarity of "identification", "represent", "QSA" and "SQA". Users can set the size of Sim( i,r,QSA,SQA) value to meet their own needs.

\section{Two way matching algorithm of quality and standard}

\subsection{Two way matching of identification and represent}

“identification”and "represent”are usually expressed in natural language. Similarity algorithm in fuzzy mathematics measures the similarity between "identification”and“represent”.

Let $\mathrm{A}$ and $\mathrm{B}$ be two vectors, where, $A=\left(X_{1}, X_{2}, \cdots, X_{N}\right), B=\left(Y_{1}, Y_{2}, \cdots, Y_{M}\right)$

1) Design the fuzzy similarity matrix $S_{A B}$, of vectors A and $\mathrm{B}, X_{i} Y_{j}$ means the similarity degree of key words and natural language meaning.

$$
S_{A B}=\left(\begin{array}{cccc}
X_{1} Y_{1} & X_{1} Y_{2} & \cdots & X_{1} Y_{m} \\
X_{2} Y_{1} & X_{2} Y_{2} & \cdots & X_{2} Y_{m} \\
\vdots & \vdots & & \vdots \\
X_{n} Y_{1} & X_{n} Y_{2} & \cdots & X_{n} Y_{m}
\end{array}\right)
$$

2) Reduce the fuzzy similarity matrix $S_{A B}$ to one dimension.

$$
\text { SemSimilarity }(A, B)=\frac{1}{n} \times \sum_{i=1}^{n}\left(\max \left(X_{i} Y_{j}\right) \quad j \in[1, m]\right.
$$

The (3) expression means to find the arithmetic mean of the maximum value of each line vector of the similar matrix. This average represents the similarity of natural language meaning between statement $\mathrm{A}$ and statement $\mathrm{B}$. In the same way, we can get the value of SemSimilarity $(B, A)$.

3) Find the fuzzy semantic similarity between sentence A and sentence B.

$$
\begin{gathered}
\text { SemSimilarity }(|A B|)=\frac{1}{2} \times(\operatorname{Sem} \text { Similarity }(A, B)+ \\
\text { SemSimilarity }(B, A))
\end{gathered}
$$


Use the above method to calculate the similarity degree of Qidentification and Sidentification,Qrepresent and Srepresent,that is, SemSimilarity(|Qidentification, Sidentification |) (Simi), and SemSimilarity(| Qrepresent, Srepresent |) (Simr). Next, we can calculate the size of $\operatorname{Sim}(\mathrm{i}, \mathrm{r})$.

$\operatorname{Sim}(i, r)=\alpha \times \operatorname{Simi}+\beta \times \operatorname{Simr}(\alpha, \beta$ are weight coefficients, satisfying $\alpha+\beta=1)$ (4)

\subsection{Two-way matching of quality attributes and standard attributes}

This paper is a two-way match of quality attributes and standard attributes. In addition to the expectation of the product quality subject on the standard provided by the standard subject in terms of standard level, standard application time range, standard application field, standard reputation, standard implementation difficulty, etc., the standard subject also has the expectation of product service life, product function perfection and product appearance novelty for quality subject.

QSA $\{$ QSAlevel,QSAtime,QSAfield,QSAreputation,QSAdifficulty\} is the indicator attribute of the quality entity to the standard entity. "QSAlevel"refers to the standard level (which can be divided into international standards, national standards, industrial standards, local standards, group standards, enterprise standards, etc.); "QSAtime"refers to the application time range of standards (such as the application time and the start and end period, etc.); "QSAfield”refers to the application field of standards (such as electronic information field, food field, drug field, mechanical product field, etc.), “QSAreputation”refers to the reputation of the standard (such as ISO9000, CMMI, etc.);“QSAdifficulty”refers to the difficulty of implementing the standard. The index attribute of the standard entity to the quality entity,SQA $=\{$ SQAlife,SQAfunction,SQAappearance $\}$ 。 "SQAlife"refers to the product service life index of the quality attribute expected by the standard subject, "SQAfunction"refers to the degree of product function perfection, and"SQAappearance”refers to the degree of product appearance novelty.

\subsubsection{Quantification of quality and standard attribute indexes}

Because it is difficult to express the attributes such as the degree of product function perfection, the degree of product appearance novelty and the standard fame with accurate numbers, we must first use an appropriate vocabulary set to express them. The vocabulary set used in this study is \{High,Relatively high, General, Relatively Low, Very low level five. Next, we need to make a quantitative transformation of the vocabulary set. Generally, the fuzzy set theory in fuzzy mathematics is used to transform. Table 1 is the vocabulary set of fuzzy set numerical measurement. 
Academic Journal of Computing \& Information Science

ISSN 2616-5775 Vol. 3, Issue 1: 1-16, DOI: 10.25236/AJCIS.030101

Table 1 Vocabulary set of fuzzy set numerical measurement

\begin{tabular}{|l|l|}
\hline Lexical set & Fuzzy set value $\left[\mu_{S A}, \nu_{S A}-\eta_{S A}\right]$ \\
\hline high & {$\left[0.9,0.1-\eta_{S A}\right]$} \\
\hline Relatively high & {$\left[0.7,0.3-\eta_{S A}\right]$} \\
\hline General & {$\left[0.5,0.5-\eta_{S A}\right]$} \\
\hline Relatively low & {$\left[0.3,0.7-\eta_{S A}\right]$} \\
\hline Very low & {$\left[0.1,0.9-\eta_{S A}\right]$} \\
\hline
\end{tabular}

We can design the vocabulary level and uncertainty of quality and standard attributes, that is $\eta_{S A}$,According to table 1 , the corresponding numerical expression of fuzzy set is obtained,that is $\left[\mu_{S A}, \nu_{S A}-\eta_{S A}\right], \mu_{S A}$ means membership, $\nu_{S A}$ means non membership, Finally, according to equation (5), the quality and standard attributes of vocabulary expression are transformed into values.

$$
\rho_{\mathrm{SA}}=\boldsymbol{\mu}_{\mathrm{SA}}-\boldsymbol{v}_{\mathrm{SA}} \times \eta_{\mathrm{SA}}
$$

\subsubsection{Standardization of quality and standard attributes}

Each quality attribute and standard attribute usually represent different meanings, and their magnitude and dimension meanings are also different. Therefore, we need to use standardized functions for standardized transformation. Formula (6) and (7) is the conversion function.

$$
\begin{gathered}
Q_{S A_{i j}}= \begin{cases}\frac{q_{S A_{i j}}-q_{S A_{j}}^{\min }}{q_{S A_{j}}-q_{S A_{j}}^{\min }} & q_{S A_{j}}^{\max }-q_{S A_{j}}^{\min } \neq 0 \\
1 & q_{S A_{j}}^{\max _{j}}-q_{S A_{j}}^{\min }=0\end{cases} \\
Q_{S A_{i j}}= \begin{cases}q_{S A_{j}}^{\max }-q_{S A_{i j}} & q_{S A_{j}}^{\max _{S}}-q_{S A_{j}}^{\min _{j}} \neq 0 \\
q_{S A_{j}}^{\max }-q_{S A_{j}}^{\min } & q_{S A_{j}}^{\max _{S}}-q_{S A_{j}}^{\min }=0\end{cases}
\end{gathered}
$$

Quality and standard attributes can be divided into positive and negative significance indicators. Positive significance indicators refer to the greater the value, the better, such as product function improvement, product appearance novelty, standard reputation, etc., which can be measured by formula (6); negative significance indicators refer to the smaller the value, the better, such as the difficulty of standard implementation, etc.,which can be used(7) To measure. Where, $q_{S A_{i j}}$ represents the jth attribute value of the ith standard subject, $q_{S A_{j}}^{\max }$ represents the maximum value compared in the jth attribute of the standard subject, and 
$q_{S A_{j}}^{\min }$ represents the minimum value compared in the jth attribute of the standard subject. Similarly, quality attributes $Q_{Q A_{i j}}$ can be standardized.

\subsubsection{Fuzzy similarity calculation of quality and standard}

After quantifying and standardizing the quality and standard attributes, we form a multi-dimensional vector. By comparing the vectors, we can measure the similarity between the quality expectation and the standard attributes SimQSA, and the similarity between the standard expectation and the quality attributes SimSQA. (8) The expression represents multidimensional vectors $C$ and $C^{\prime}$.

$$
\begin{gathered}
C=\left(C_{1}, C_{2}, \cdots, C_{n}\right) \\
C^{-}=\left(C_{1}^{-}, C_{2}^{-}, \cdots, C_{n}^{-}\right)
\end{gathered}
$$

In this study, the cosine method is used to measure the magnitude of similarity between two vectors, that is, the smaller the angle between two vectors, the higher the similarity between two vectors. The calculation and measurement method is formula (9):

$$
\begin{aligned}
\operatorname{Sim}\left(C, C^{-}\right) & =\cos \left(C, C^{-}\right)=\frac{C \cdot C^{-}}{\|C\| \times\left\|C^{-}\right\|}= \\
& \frac{\sum_{j=1}^{n} C_{j} \cdot C_{j}^{\prime}}{\sqrt{\sum_{j=1}^{n} C_{j}^{2} \cdot \sum_{j=1}^{n} C_{j}^{-2}}}
\end{aligned}
$$

The vector of the standard attribute index expected by the quality subject after standardized transformation is:

$$
\mathrm{Q}_{\mathrm{SA}}^{\prime}=\left\{\mathrm{Q}^{\prime}{ }_{\mathrm{SA} 1}, \mathrm{Q}_{\mathrm{SA} 2}^{\prime}, \mathrm{Q}^{\prime}{ }_{\mathrm{SA} 3}, \mathrm{Q}_{\mathrm{SA} 4}^{\prime}, \mathrm{Q}^{\prime} \mathrm{SA}\right\}
$$
is:

The quality attribute standardization index vector of standard subject expectation

$$
\mathrm{S}^{\prime}{ }_{\mathrm{QA}}=\left\{\mathrm{S}^{\prime}{ }_{\mathrm{QA} 1}, \mathrm{~S}^{\prime}{ }_{\mathrm{QA} 2}, \mathrm{~S}^{\prime}{ }_{\mathrm{QA} 3}\right\}
$$

The quality attribute standardization index vector provided by the quality subject is:

$$
\mathrm{Q}_{\mathrm{QA}}^{\prime}=\left\{\mathrm{Q}_{\mathrm{QA} 1}^{\prime}, \mathrm{Q}^{\prime} \mathrm{QA}_{2}, \mathrm{Q}_{\mathrm{QA} 3}^{\prime}\right\}
$$

The standard attribute standardization index vector provided by the standard subject is:

$$
\mathrm{S}_{\mathrm{SA}}^{\prime}=\left\{\mathrm{S}_{\mathrm{SA} 1}^{\prime}, \mathrm{S}_{\mathrm{SA} 2}^{\prime}, \mathrm{S}_{\mathrm{SA}}^{\prime}, \mathrm{S}_{\mathrm{SA} 4}^{\prime}, \mathrm{S}_{\mathrm{SA} 5}^{\prime}\right\}
$$

Through equation (9),calculate the similarity SimQSA from the standard attribute 
( $\mathrm{Q}_{\mathrm{SA}}$ ) expected by the quality subject to the standard attribute ( $\mathrm{S}_{\mathrm{SA}}^{\prime}$ ) provided by the standard subject, and the similarity SimSQA from the quality attribute $\left(\mathrm{S}^{\prime}{ }_{\mathrm{QA}}\right)$ expected by the standard subject to the quality attribute $\left(\mathrm{Q}^{\prime}{ }_{\mathrm{QA}}\right)$ provided by the quality subject. Then, the similarity value $\operatorname{sim}(Q S A, S Q A)$ of two-way matching between quality and standard attribute is calculated by equation (14). In the equation, $\gamma, \delta$ represent weight coefficient, which satisfies $\gamma+\delta=1$. Equation (14) is as follows:

$$
\operatorname{Sim}(\mathrm{QSA}, \mathrm{SQA})=\gamma \times \operatorname{SimQSA}+\delta \times \operatorname{SimSQA} \quad(14) \text {. }
$$

In this way, according to the values of $\operatorname{Sim}(\mathrm{i}, \mathrm{r})$ and $\operatorname{Sim}(\mathrm{QSA}, \mathrm{SQA})$, the value of fuzzy similarity $\operatorname{sim} \operatorname{Sim}(\mathrm{i}, \mathrm{r}, \mathrm{Q}$ A,SQA) can be calculated. See equation (15) for the calculation formula, where, $\omega_{1}, \omega_{2}$ is the weight coefficient, satisfying $\omega_{1}+\omega_{2}=1$. Equation (15) is as follows:

$$
\operatorname{Sim}(i, r, Q S A, S Q A)=\omega_{1} \times \operatorname{Sim}(i, r)+\omega_{2} \times \operatorname{Sim}(Q S A, S Q A)
$$

Finally, according to the size of $\operatorname{Sim}(i, r, Q S A, S Q A)$, the combination sequence of product quality and standard meeting the requirements is output.

\section{Experimental verification}

In this study, JDK 8, eclipse 4.6 and SQL Server 2014 software are used as the development environment, Tomcat 8.0 is used as the middleware to build the product quality and standard two-way matching experiment platform for simulation experiment, and using Java programming language to develop program,next,select and call the product quality and standard two-way matching. The main body of product standard puts forward the requirements for the main body of product quality when it publishes the standard; the main body of product quality selects the required standards through the standard attributes, and the platform system extracts data from the database according to the conditions set by both sides to match the product quality and the standard in two ways.

Taking the two-way matching of men's shirts product quality and standard as an example, 18 kinds of men's shirt products are randomly selected from the market (this paper is from Tmall mall), and expressed by $\mathrm{Qj}(\mathrm{j}=1,2, \ldots, 18)$. There are 4 kinds of men's shirt standards in the standard library (using S1, S2, S3, S4 to express), which need two-way matching between men's shirt products and standards.

According to the description of the product quality and standard two-way matching, according to the calculated similarity value output to meet the requirements of product quality and standard combination sequence.

Users can set the appropriate similarity value according to their needs. In formula (4), the weight coefficients $\alpha$ and $\beta$ are 0.5 , and the similarity value is set to $\operatorname{Sim}(\mathrm{i}, \mathrm{r}) \geq 0.7300$. The two-way matching results of identification and represent of 4 standards and 18 men's shirts are shown in Table 2. 
Academic Journal of Computing \& Information Science

ISSN 2616-5775 Vol. 3, Issue 1: 1-16, DOI: 10.25236/AJCIS.030101

Table 2 Two way matching results of identification and represent

\begin{tabular}{|l|l|l|l|l|}
\hline Qi/ Sj & S1 & S2 & S3 & S4 \\
\hline Q1 & 0.7472 & 0.8291 & 0.7752 & 0.9465 \\
\hline Q2 & 0.9485 & 0.7062 & 0.7181 & 0.6593 \\
\hline Q3 & 0.9520 & 0.7855 & 0.5937 & 0.6321 \\
\hline Q4 & 0.5629 & 0.9328 & 0.9415 & 0.9373 \\
\hline Q5 & 0.9041 & 0.5470 & 0.8427 & 0.5936 \\
\hline Q6 & 0.8729 & 0.6523 & 0.5438 & 0.6952 \\
\hline Q7 & 0.5417 & 0.6285 & 0.6914 & 0.6177 \\
\hline Q8 & 0.6153 & 0.9127 & 0.7490 & 0.8925 \\
\hline Q9 & 0.8241 & 0.5632 & 0.6403 & 0.6539 \\
\hline Q10 & 0.5429 & 0.9805 & 0.8927 & 0.6582 \\
\hline Q11 & 0.5930 & 0.7628 & 0.6351 & 0.9623 \\
\hline Q12 & 0.5724 & 0.8357 & 0.9135 & 0.7042 \\
\hline Q13 & 0.5921 & 0.6831 & 0.5538 & 0.6275 \\
\hline Q14 & 0.7612 & 0.5927 & 0.6724 & 0.8015 \\
\hline Q15 & 0.5479 & 0.8513 & 0.7035 & 0.6740 \\
\hline Q16 & 0.8526 & 0.5621 & 0.7521 & 0.6829 \\
\hline Q17 & 0.9135 & 0.8215 & 0.6724 & 0.5361 \\
\hline Q18 & 0.6237 & 0.8392 & 0.9217 & 0.8052 \\
\hline
\end{tabular}

According to the 4 standards of 18 kinds of men's shirt product quality expectations, the two-way matching of quality and standard attributes is made. The standard attribute indexes of product quality subject expectation are: standard level, standard application time range, standard application field, standard reputation and standard implementation difficulty; the quality attributes of standard subject expectation are: product service life, product function improvement process and product appearance novelty. Among them, standard level agreement, international standard is represented by 1 , national standard by 2 , industrial standard by 3 , local standard by 4 , group standard by 5 , enterprise standard by 6 .

Table 3 shows the quality attributes of men's shirts and the expectations of quality subjects for standard attributes.

Table 4 shows the standard attributes and the expectation of the standard subject for quality attributes.

According to table 1 and formula (5), this study makes quantitative transformation for the language meaning expression in Table 3 and table 4, and the uncertainty $\eta_{S A}$ is set by the end user according to the actual needs. In order to facilitate the comparison, the numerical value after quantification is standardized in this study. Formula (6) is used to standardize the size of the standard reputation, the degree of product function perfection, and the degree of product appearance novelty, while formula (7) is used to standardize the size of the standard difficulty. After the standardized transformation processing, similarity calculation is carried out. The expectation of 16 quality Qi for standard attributes is set as 16 groups of 5-Dimensional vectors, and the standard attributes of 4 standard SJ are set as 4 groups of 5-Dimensional vectors. Then, formula (9) is used to do one-to-one 
Academic Journal of Computing \& Information Science

ISSN 2616-5775 Vol. 3, Issue 1: 1-16, DOI: 10.25236/AJCIS.030101

matching operation from product quality to standard. In the same way, we can do the one-to-one matching operation from product standard to quality.

Table 5 is the similarity value of the standard attribute and the quality subject's expectation of two-way matching of the standard attribute.

Table 5 Similarity value of standard attribute and quality subject's expectation for two-way matching of standard attribute

\begin{tabular}{|c|c|c|c|}
\hline S1/Qi & Sim(SQA1,QSA) & S2/Qi & Sim(SQA2,QSA) \\
\hline Q1 & 0.4617 & Q1 & 0.9253 \\
\hline Q2 & 0.8035 & Q3 & 0.8126 \\
\hline Q3 & 0.9930 & Q4 & 0.8651 \\
\hline Q5 & 0.8625 & Q8 & 0.7938 \\
\hline Q6 & 0.9531 & Q10 & 0.9422 \\
\hline Q9 & 0.7452 & Q11 & 0.8057 \\
\hline Q14 & 0.9427 & Q12 & 0.8920 \\
\hline Q16 & 0.9623 & Q15 & 0.8842 \\
\hline Q17 & 0.9275 & Q17 & 0.8361 \\
\hline & - & Q18 & 0.8573 \\
\hline S3/Qi & Sim(SQA3,QSA) & S4/Qi & Sim(SQA4,QSA) \\
\hline Q1 & 0.9738 & Q1 & 0.8915 \\
\hline Q4 & 0.8733 & Q4 & 0.7640 \\
\hline Q5 & 0.7926 & Q8 & 0.8759 \\
\hline Q8 & 0.9125 & Q11 & 0.9627 \\
\hline Q10 & 0.9470 & Q14 & 0.3548 \\
\hline Q12 & 0.8924 & Q18 & 0.8136 \\
\hline Q16 & 0.4193 & \multirow{2}{*}{\multicolumn{2}{|c|}{-}} \\
\hline Q18 & 0.9362 & & \\
\hline
\end{tabular}

Next, we can calculate Sim(i,r,QSA,SQA). In formula (15),the weight coefficient $\omega_{1}$ is $0.7, \omega_{2}$ is 0.3 , and the similarity requirement is $\operatorname{Sim}(\mathrm{i}, \mathrm{r}, \mathrm{QSA}, \mathrm{SQA}) \geq 0.7600$.In this way, the matching results of 18 kinds of men's shirt products and 4 kinds of standards are calculated, as shown in Table 6.

Table 6 Similarity value of SJ and Qi bidirectional matching

\begin{tabular}{|l|l|l|l|}
\hline S1/Qi & Sim(i,r,SQA1,QSA) & S2/Qi & Sim(i,r,SQA2,QSA) \\
\hline Q2 & 0.9026 & Q1 & 0.8632 \\
\hline Q3 & 0.9815 & Q3 & 0.8014 \\
\hline Q5 & 0.8923 & Q4 & 0.9173 \\
\hline Q6 & 0.9285 & Q8 & 0.8951 \\
\hline Q14 & 0.9307 & Q10 & 0.9732 \\
\hline Q16 & 0.8740 & Q11 & 0.7835 \\
\hline Q17 & 0.9152 & Q12 & 0.8510 \\
\hline \multirow{2}{*}{} & - & Q15 & 0.8819 \\
\cline { 3 - 4 } & Q17 & 0.8372 \\
\cline { 3 - 4 } & Q18 & 0.8795 \\
\hline S3/Qi & Sim(i,r,SQA3,QSA) & S4/Qi & Sim(i,r,SQA4,QSA) \\
\hline
\end{tabular}

Published by Francis Academic Press, UK

-11 - 
Academic Journal of Computing \& Information Science

ISSN 2616-5775 Vol. 3, Issue 1: 1-16, DOI: 10.25236/AJCIS.030101

\begin{tabular}{|l|l|l|c|}
\hline Q1 & 0.8851 & Q1 & 0.9302 \\
\hline Q4 & 0.9564 & Q4 & 0.8931 \\
\hline Q5 & 0.8537 & Q8 & 0.8725 \\
\hline Q8 & 0.8366 & Q11 & 0.9617 \\
\hline Q10 & 0.9270 & Q18 & 0.8294 \\
\cline { 1 - 2 } Q12 & 0.8913 & \multicolumn{2}{|c}{-} \\
\cline { 1 - 2 } Q18 & 0.9328 & & \\
\cline { 1 - 2 }
\end{tabular}

In order to facilitate the visual comparison of the quality of 18 kinds of men's shirts and the control matching effect of 4 kinds of standards, the two-way matching results of product quality Qi and standard SJ are listed according to the calculation results in Table 6, as shown in Table 7.

Table 7 Two way matching results of product quality Qi and standard Sj

\begin{tabular}{|l|l|}
\hline standard Sj & Matching degree ranking of corresponding quality Qi \\
\hline S1 & Q3 $>$ Q14 $>$ Q6 $>$ Q17 $>$ Q2 $>$ Q5 $>$ Q16 \\
\hline S2 & Q10 $>$ Q4 $>$ Q8 $>$ Q15 $>$ Q18 $>$ Q1 $>$ Q12 $>$ Q17 $>$ Q3 $>$ Q11 \\
\hline S3 & Q4 $>$ Q18 $>$ Q10 $>$ Q12 $>$ Q1 $>$ Q5 $>$ Q8 \\
\hline S4 & Q11 $>$ Q1 $>$ Q4 $>$ Q8 $>$ Q18 \\
\hline
\end{tabular}

It can be seen from Table 6 and Table 7 that in the case of setting similarity requirements $(\geq 0.7600$ ), for standard $\mathrm{S} 1$, the matching results that meet the requirements are:Q3>Q14 $>\mathrm{Q} 6>\mathrm{Q} 17>\mathrm{Q} 2>\mathrm{Q} 5>\mathrm{Q} 16$. It can be seen that the matching degree of Q3 of the third kind of men's shirt with standard S1 is the highest, reaching 0.9815; then q14, Q6, Q17, Q2, Q5 and Q16 of men's shirt match with standard S1 The lowest degree is 0.8740 , while the matching degree of other products is less than 0.7600 , which does not meet the set requirements.

For standard S2, among the 18 kinds of men's shirts, the matching results that meet the requirements are: Q10 $>\mathrm{Q} 4>\mathrm{Q} 8>\mathrm{Q} 15>\mathrm{Q} 18>\mathrm{Q} 1>\mathrm{Q} 12>\mathrm{Q} 17>\mathrm{Q} 3>\mathrm{Q} 11$. It can be seen that the matching degree between Q10 and standard S2 is the highest, reaching 0.9732; then it is Q4, Q8, Q15, Q18, Q1, Q12, Q17, Q3, Q11; the matching degree between Q11 and standard S2 is the lowest, is 0.7835 , while that of other products is the lowest The matching degree is less than 0.7600 , which does not meet the requirements.

For standard S3, among the 18 kinds of men's shirt products, the matching results that meet the requirements are: $\mathrm{Q} 4>\mathrm{Q} 18>\mathrm{Q} 10>\mathrm{Q} 12>\mathrm{Q} 1>\mathrm{Q} 5>\mathrm{Q} 8$. It can be seen that the matching degree of the fourth kind of men's shirt Q4 and standard S3 is the highest, reaching 0.9564; then it is Q18, Q10, Q12, Q1, Q5, Q8 in turn, the matching degree of the eighth kind of men's shirt Q8 and standard S3 is the lowest,is 0.8366 , while the matching degree of other kinds of products is less than 0.7600 , which does not meet the requirements.

For standard S4, among the 18 kinds of men's shirt products, the matching results that meet the requirements are: Q11 $>\mathrm{Q} 1>\mathrm{Q} 4>\mathrm{Q} 8>\mathrm{Q} 18$. It can be seen that the matching degree of the 11th kind of men's shirt Q11 and standard S4 is the highest, reaching 0.9617; then it is Q1, Q4, Q8, Q18 in turn, the matching degree of the 18th kind of men's shirt Q18 and standard S4 is the lowest, which is 0.8294, 
while the matching degree of other kinds of products is less than 0.7600 , which does not meet the set requirements.

\section{Conclusions}

Aiming at the limitation of the research on the two-way matching of product quality and standard at home and abroad, based on the theory of fuzzy similarity in fuzzy mathematics, this paper discusses the two-way matching model of product quality and standard, and randomly selects 18 kinds of men's shirt machine products from Tmall Mall, and carries out the two-way matching experiment of product quality and standard with the designed standard. Through experimental verification, it is found that the two-way matching model of product quality and standard given in this study is a universal, scientific and reasonable two-way matching model of product quality and standard, which supports most of the two-way matching of product quality and standard. It not only enriches the two-way matching theory of product quality and standard, but also can be applied to the practice of economic and social development. The model supports the two-way automatic matching of product quality and standard, and provides an important methodological support for the research of common technology of National Quality Infrastructure (NQI).

\section{Acknowledgements}

This study is supported by the National Key Research and Development Project: "Internet + "NQI integrated services generic technology (No.2017YFF0209600), in particular,Projects 1:Research on NQI integrated service basic theory and general standard (No.2017YFF0209601).

About the author:

Zhaojun Wang, male,senior engineer, Beijing Sunway World Science \& Technology Co.,Ltd; Research direction: Intelligent manufacturing, Data governance, Inspection and testing informatization, Big data technology, etc..

Liangwen Yue(corresponding author), male,senior engineer,Ph.D./Postdoctoral; Beijing Sunway World Science \& Technology Co.,Ltd; Research direction:Internet technology, Big data technology, Artificial intelligence technology, Quality management, etc.; E-mail: liangwenylw@163.com; address:Beijing Sunway World Science \& Technology Co.,Ltd;Bldg 12,Yard 6, Haiying Road, Fengtai District, Beijing, China, 100070.

\section{References}

[1] Li Bingrong, Pei Daowu. Restricted Equivalence Functions and Fuzzy Similarity Measures [J]. Fuzzy system and mathematics, 2018,32 (4): 36-45.

[2] Liu Jiubing, Zhou Xianzhong, Li Huaxiong, Huang Bing, Gu Pingping. An intuitionistic fuzzy three-way decision method based on intuitionistic fuzzy 
Academic Journal of Computing \& Information Science

ISSN 2616-5775 Vol. 3, Issue 1: 1-16, DOI: 10.25236/AJCIS.030101

similarity degrees [J]. System engineering theory and practice, 2019,39 (6): 1550-1564.

[3] Zheng Gao, pan Ling, Chen Rui. Research on Similarity Measure between Type-1 Fuzzy Sets [J]. Informatization Research, 2018, 44 (5), 41-43.

[4] Zhao Tao, Xiao Jian. Similarity measure between type-2 fuzzy sets and its applications[J]. Computer engineering and applications, 2013,49 (8): 22-26.

[5] Huang Wensi, Chen Jing, Gu Yu. Research on Intelligent Data Matching and Recognition Scheme Based on Big Data Technology [J]. Telecom Power Technology, 2019,36 (5): 161-165.

[6] Gao Tong. Approximation Performance and Localization Algorithm of Generalized Mamdani Fuzzy Systems structed Based on Fuzzy Similarity. [D]. Dissertation of Tianjin Normal University, 2018.

[7] Li Peng, Zhu Jianjun. Multiple Attribute Large-scaled Group Decision Making Methods Based on New Intuitionistic Fuzzy Similarity Degree [J]. Operations Research and Management Science, 2014, 23 (2), 167-174.

[8] Wu Yitao, Zhang Xingming, Wang Xingmao, Li Han. User fuzzy similarity-based collaborative filtering recommendation algorithm [J]. Journal of communications, 2016, 37, (1): 198-206.

[9] Wang lingran, Li Dengfeng. A TOPSIS Method Based on Intuitionistic Fuzzy Similarity and Its Application [J]. Science and technology management research, 2017,19:210-216.

[10] Zhang Bin, Yuan Zhengyi, Zhao Xuesheng, Zhang Xinjian. An Geometry Deformation Evaluation Index of the Spherical Discrete Grid Based on the Fuzzy Similarity [J]. Geography and Geo-Information Science, 2015, (5): 24-33.

[11] Yuan Zehua, Pan Xiaodong. Clustering Method Based on New Intuitionistic Fuzzy Similarity Degree [J]. Journal of Luoyang Institute of Science and Technology ( Natural Science Edition), 2017 (4): 85-89.

[12] Mathews S C,Demski R,Hooper J E,et al.A Model for the Departmental Quality Management Infrastructure within an Academic Health system[J].Academic Medicine,2017,92(5):608-613.

[13] Yumeng Miao,Rong Du,Jin Li,et al.A two-sided matching model in the context of B2B export cross-border e-commerce[J]. Electronic Commerce Research, 2019, 19 (5):841-861.

[14] Li Y, Fang J, Zeng Y, et al.Two-sided online bipartite matching in spatial data: experiments and analysis [J].GeoInformatica, 2019(13):1-24.

[15] Wan R,Xiong N,Hu Q,et al.Similarity-aware data aggregation using fuzzy c-means approach for wireless sensor networks[J].EURASIP Journal on Wireless Communications and Networking,2019,59(1):1-11.

[16] Hussian Zahid,Yang Miin-Shen.Distance and similarity measures of Pythagorean fuzzy sets based on the Hausdorff metric with application to fuzzy TOPSIS[J]. International Journal of Intelligent Systems, 2019,34(10):2633-2654. 
Table 3 Quality attribute and quality subject's expectation for standard attribute

\begin{tabular}{|c|c|c|c|c|c|c|c|c|c|c|c|c|}
\hline & \multicolumn{5}{|c|}{ Product quality attribute } & \multicolumn{7}{|c|}{ Quality subject's expectation of standard attribute } \\
\hline \multirow[t]{2}{*}{$\begin{array}{l}\text { Quality } \\
\text { (Qi) }\end{array}$} & \multirow[t]{2}{*}{$\begin{array}{l}\text { Service } \\
\text { life (year) }\end{array}$} & \multicolumn{2}{|l|}{$\begin{array}{l}\text { Function } \\
\text { perfection }\end{array}$} & \multicolumn{2}{|c|}{$\begin{array}{l}\text { Appearance } \\
\text { novelty }\end{array}$} & \multirow{2}{*}{$\begin{array}{l}\text { Number of } \\
\text { application } \\
\text { areas }\end{array}$} & \multirow{2}{*}{$\begin{array}{l}\text { Applicable } \\
\text { time period } \\
\text { (year) }\end{array}$} & \multirow[t]{2}{*}{$\begin{array}{l}\text { Standard } \\
\text { grade }\end{array}$} & \multicolumn{2}{|l|}{ Fame } & \multicolumn{2}{|c|}{ Degree of difficulty } \\
\hline & & Grade & $\eta_{S A}$ & Grade & $\eta_{S A}$ & & & & Grade & $\eta_{S A}$ & Grade & $\eta_{S A}$ \\
\hline Q1 & 2 & $\begin{array}{l}\text { Relatively } \\
\text { high }\end{array}$ & 0.2 & $\begin{array}{l}\text { Relatively } \\
\text { high }\end{array}$ & 0.2 & 2 & 3 & 2 & $\begin{array}{l}\text { Relatively } \\
\text { high }\end{array}$ & 0.2 & General & 0.1 \\
\hline Q2 & 2.5 & High & 0.4 & $\begin{array}{l}\text { Relatively } \\
\text { high }\end{array}$ & 0.3 & 4 & 6 & 5 & $\begin{array}{l}\text { Relatively } \\
\text { high }\end{array}$ & 0.3 & $\begin{array}{l}\text { Relatively } \\
\text { high }\end{array}$ & 0.2 \\
\hline Q3 & 2 & $\begin{array}{l}\text { Relatively } \\
\text { high }\end{array}$ & 0.2 & $\begin{array}{l}\text { Relatively } \\
\text { high }\end{array}$ & 0.2 & 4 & 5 & 3 & High & 0.4 & High & 0.3 \\
\hline $\mathrm{Q} 4$ & 2 & $\begin{array}{l}\text { Relatively } \\
\text { high }\end{array}$ & 0.3 & General & 0.1 & 3 & 4 & 2 & $\begin{array}{l}\text { Relatively } \\
\text { high }\end{array}$ & 0.2 & $\begin{array}{l}\text { Relatively } \\
\text { high }\end{array}$ & 0.2 \\
\hline Q5 & 1.5 & General & 0.2 & $\begin{array}{l}\text { Relatively } \\
\text { high }\end{array}$ & 0.3 & 3 & 3 & 3 & $\begin{array}{l}\text { Relatively } \\
\text { high }\end{array}$ & 0.3 & High & 0.3 \\
\hline Q6 & 1 & General & 0 & High & 0.3 & 2 & 3 & 6 & High & 0.3 & $\begin{array}{l}\text { Relatively } \\
\text { high }\end{array}$ & 0.2 \\
\hline Q7 & 4 & High & 0.3 & High & 0.4 & 5 & 5 & 1 & High & 0.4 & High & 0.4 \\
\hline Q8 & 1.5 & General & 0.2 & General & 0 & 2 & 4 & 3 & General & 0.1 & $\begin{array}{l}\text { Relatively } \\
\text { high }\end{array}$ & 0.3 \\
\hline $\begin{array}{l}\text { Q9 } \\
\end{array}$ & 3 & $\begin{array}{l}\text { High } \\
\text { nal }\end{array}$ & 0.3 & General & 0.1 & 4 & 3 & 5 & High & 0.3 & High & 0.3 \\
\hline Q10 & 2 & General & 0.1 & $\begin{array}{l}\text { Relatively } \\
\text { high }\end{array}$ & 0.3 & 2 & 6 & 3 & General & 0.2 & General & 0.2 \\
\hline Q11 & 1 & General & 0.1 & General & 0.2 & 3 & 3 & 4 & General & 0.1 & General & 0.1 \\
\hline Q12 & 2 & General & 0.1 & General & 0.2 & 3 & 5 & 3 & General & 0.1 & General & 0.2 \\
\hline Q13 & 1.5 & General & 0.2 & General & 0 & 2 & 4 & 3 & General & 0 & General & 0 \\
\hline Q14 & 3.5 & High & 0.4 & High & 0.3 & 5 & 5 & 6 & High & 0.4 & High & 0.4 \\
\hline Q15 & 0.5 & $\begin{array}{l}\text { Relatively } \\
\text { Low }\end{array}$ & 0 & General & 0.1 & 2 & 4 & 4 & General & 0 & General & 0.1 \\
\hline Q16 & 4 & High & 0.4 & High & 0.3 & 5 & 5 & 1 & High & 0.3 & High & 0.4 \\
\hline Q17 & 2 & $\begin{array}{l}\text { Relatively } \\
\text { high }\end{array}$ & 0.3 & $\begin{array}{l}\text { Relatively } \\
\text { high }\end{array}$ & 0.3 & 3 & 4 & 2 & High & 0.3 & $\begin{array}{l}\text { Relatively } \\
\text { high }\end{array}$ & 0.3 \\
\hline Q18 & 2 & $\begin{array}{l}\text { Relatively } \\
\text { high }\end{array}$ & 0.3 & General & 0.2 & 3 & 4 & 2 & $\begin{array}{l}\text { Relatively } \\
\text { high }\end{array}$ & 0.2 & $\begin{array}{l}\text { Relatively } \\
\text { high }\end{array}$ & 0.3 \\
\hline
\end{tabular}


Table 4 Standard attributes and standard subjects' expectation for quality attributes

\begin{tabular}{|c|c|c|c|c|c|c|c|c|c|c|c|c|}
\hline \multicolumn{8}{|c|}{ Standard attribute } & \multicolumn{5}{|c|}{$\begin{array}{l}\text { Standard subject's expectation of quality } \\
\text { attribute }\end{array}$} \\
\hline \multirow[t]{2}{*}{ standard $(\mathrm{Sj})$} & \multirow[t]{2}{*}{$\begin{array}{l}\text { Application } \\
\text { field }\end{array}$} & \multirow{2}{*}{$\begin{array}{l}\text { Applicable } \\
\text { time period } \\
\text { (year) }\end{array}$} & \multirow[t]{2}{*}{$\begin{array}{l}\text { Standard } \\
\text { grade }\end{array}$} & \multicolumn{2}{|l|}{ Fame } & \multicolumn{2}{|c|}{$\begin{array}{l}\text { Degree of } \\
\text { difficulty }\end{array}$} & \multirow{2}{*}{$\begin{array}{l}\text { service } \\
\text { life } \\
\text { (year) }\end{array}$} & \multicolumn{2}{|c|}{$\begin{array}{l}\text { function } \\
\text { perfection }\end{array}$} & \multicolumn{2}{|c|}{$\begin{array}{l}\text { appearance } \\
\text { novelty }\end{array}$} \\
\hline & & & & Grade & $\eta_{S A}$ & Grade & $\eta_{S A}$ & & Grade & $\eta_{S A}$ & Grade & $\eta_{s}$ \\
\hline S1 & 4 & 5 & 2 & $\begin{array}{l}\text { Relativel } \\
\text { y high }\end{array}$ & 0.3 & High & 0.4 & 4 & $\begin{array}{l}\text { Relativel } \\
\text { y high }\end{array}$ & 0.3 & High & 0.2 \\
\hline S2 & 3 & 6 & 2 & $\begin{array}{l}\text { Relativel } \\
\text { y high }\end{array}$ & 0.3 & High & 0.3 & 4 & $\begin{array}{l}\text { Relativel } \\
\text { y high }\end{array}$ & 0.3 & High & 0.3 \\
\hline S3 & 5 & 4 & 3 & $\begin{array}{l}\text { Relativel } \\
\text { y high }\end{array}$ & 0.2 & $\begin{array}{l}\text { Relativel } \\
\text { y high }\end{array}$ & 0.2 & 3 & General & 0.2 & $\begin{array}{l}\text { Relativel } \\
\text { y high }\end{array}$ & 0.1 \\
\hline S4 & 2 & 7 & 1 & High & 0.4 & High & 0.4 & 5 & High & 0.4 & High & 0.4 \\
\hline
\end{tabular}

